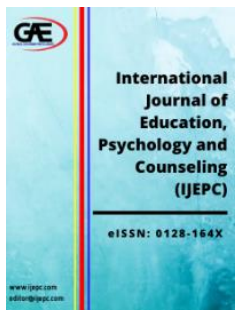

\author{
INTERNATIONAL JOURNAL OF \\ EDUCATION, PSYCHOLOGY \\ AND COUNSELLING \\ (IJEPC) \\ www.ijepc.com
}

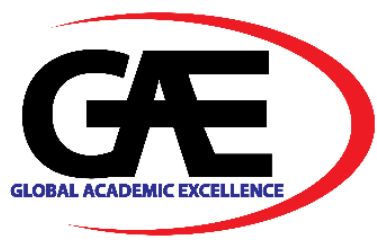

\title{
REDUCING DEPRESSION IN PREGNANCY AND POSTPARTUM PERIOD THROUGH ACCEPTANCE AND COMMITMENT THERAPY: A REVIEW OF DEPRESSION REDUCTION AMONG IRANIAN WOMEN
}

\author{
Nastaranalsadat Hosseini ${ }^{1}$, Poh Li Lau ${ }^{2}$, Diana-Lea Baranovich ${ }^{3}$, Norsafatul Aznin A.Razak ${ }^{4}$
}

1 Faculty of Education, University Malaya (UM), Malaysia

Email: nastaran62h@gmail.com

2 Faculty of Education, University Malaya (UM), Malaysia

Email: janicepolly@um.edu.my

3 Faculty of Education, University Malaya (UM), Malaysia

Email: dr.dileab@gmail.com

$4 \quad$ Faculty of Education, University Malaya (UM), Malaysia

Email: safatul@um.edu.my

* Corresponding Author

\section{Article Info:}

Article history:

Received date: 15.10 .2020

Revised date: 01.11.2020

Accepted date: 13.11 .2020

Published date: 03.12.2020

To cite this document:

Hosseini, N., Poh, L. L., Baranovich, D. L. \& A.Razak, N. A. (2020). Reducing Depression in Pregnancy and Postpartum Period Through Acceptance and Commitment Therapy: A Review of Depression Reduction among Iranian Women. International Journal of Education, Psychology and Counseling, 5 (37), 232-244.
Abstract:

Pregnancy is an important event in the life of every woman that is associated with conflicting emotions. Having a newborn baby can be accompanied by hardships and loss of desire, as well as other stresses in life, all of which can have adverse effects on the mental health of the mother and her family. Depression is a common mental disorder in mothers during and after childbirth, which can have negative consequences for mother and baby. Acceptance and Commitment Therapy (ACT) is one of the new treatments with a positive impact on the reduction of depression during pregnancy and afterward. This form of psychotherapy is significant in increasing the psychological flexibilities of women as well as reducing their distress and depressive symptoms during pregnancy and during the postpartum period. Hence this paper aims to review the literature on the concept of depression, its symptoms, and outcomes during pregnancy and the postpartum period, and subsequently, it reviews how ACT can reduce depression, in terms of relevance to Iranian mothers. The studies were selected and identified through online databases from relevant published articles in psychology, psychotherapy, and mental health journals. The reviews of the literature on the ACT and reducing depression in pregnancy and postpartum period were identified from research studies in Iran from 2015 to the present time. This paper highlights the 


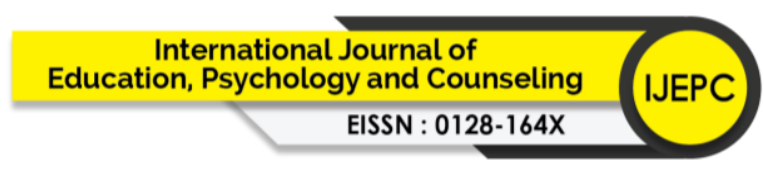

Volume 5 Issue 37 (December 2020) PP. 232-244

DOI 10.35631/IJEPC.5370019

DOI: $10.35631 /$ IJEPC.5370019.

This work is licensed under $\underline{\mathrm{CC} B Y} 4.0$

(1) significance of future research into ACT for reducing depression during pregnancy and the postpartum period among Iranian women.

Keywords:

Depression; Acceptance and Commitment Therapy; Pregnant Women, Postpartum Depression

\section{Introduction}

Pregnancy is a frequent occurrence among women of reproductive age. Pregnancy is considered to be a joyful, happy, and developing experience in the life of every woman. (Setse et al., 2009). The transition to motherhood brings new self-esteem for women and enables them to confront issues with their own values and possibly create new values and identities (Carin, Lundgren, \& Bergbom, 2011). Hall (2006), has been stated that the birth of a child can have a significant effect on the personal wholeness of a woman. Through such positive development however, many women are faced with many physiological changes and hormonal as well as the need for psychological adaptation during the childbearing process and postpartum period. These dynamic changes may cause two opposite feelings of joy and frustration at the same time as they are not merely adaptive (Carin et al., 2011; Shi \& MacBeth, 2017), and they may lastly be reasons for the mental disorders of some mothers (Barba-Müller, Craddock, Carmona, \& Hoekzema, 2019; George, Luz, De Tychey, Thilly, \& Spitz, 2013). Thus, the mental and physical health of women during and after pregnancy is very important and needs special care, attention, and support. According to the World Health Organization (WHO), today one of the major public health challenges is maternal mental health disorders. The WHO reported that almost $10 \%$ of pregnant women and $13 \%$ in the postpartum period experience mental disorder. In developing countries this rate can be even higher with $15.6 \%$ during pregnancy and $19.8 \%$ after childbirth. Globally, depression is first and foremost a disorder that women experience during both of these periods. In developing countries some $20 \%$ of mothers experience clinical depression in the postpartum period (World Health Organization, 2020). Previous studies in Iran reported that the overall prevalence of depression was $41.22 \%$ during pregnancy (Azami et al., 2018) and $28.7 \%$ in the postpartum time (Veisani \& Sayehmiri, 2012).

Any maternal mental disorder negatively affects the life and health of a family, primarily the children. The daily needs of children and the necessary level of care such as breastfeeding and mother-infant attachment may be negatively affected by the mental disorder. Therefore, children may have low weight at the point of birth and after, they may not grow perfectly and as a result they experience behavioural, cognitive, and socio-emotional problems in their life (Kingston \& Tough, 2014). However, maternal mental disorders are treatable and adequate intervention may be effective for preventing such development of disorders. Acceptance and Commitment Therapy (ACT) is a novel, experimental supported therapy that has been effectively implemented for treating maternal depression during and after pregnancy.

\section{Depression during Pregnancy and the Postpartum Period}

The tendency of reducing capability of healthy growth and development of everyone in life may be due to the most common psychological disorder which is depression. Depression is a long-term experience of emotions of intense sadness, low mood, or feeling great levels of miserableness (Jorm, Allen, Morgan, \& Purcell, 2013). Depression is not only a feeling, but 


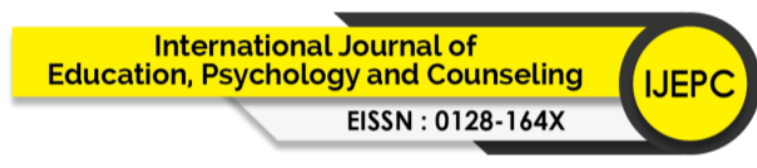

Volume 5 Issue 37 (December 2020) PP. 232-244

DOI 10.35631/IJEPC.5370019

also an action. Depression is a lack of pleasure and interest in taking part in the usual activities of life. Thus, its symptoms can appear in feelings, thoughts, behaviours, and physical changes (Bahrami \& Bahrami, 2013; Gotlib \& Hammen, 2008; Lam, 2018). Although there is no clear cause for such psychological disorders, a combination of genetic, environmental, and personal factors may be linked with developing depression. Based on the WHO report, depression was and is the fourth and second most common mental disorder around the world in 1990 and 2020, respectively (Murray, Lopez, \& Organization, 1996). In addition it affected the physical and mental health of more than 264 million males and females of any age (World Health Organization, 2017). However, the number of women affected by depression is generally more than for men. One of the reasons may be due to the experience of women during pregnancy. During pregnancy and mostly in the postpartum period women experience depression (Bowen, Bowen, Butt, Rahman, \& Muhajarine, 2012; Slomian, Honvo, Emonts, Reginster, \& Bruyère, 2019), whilst the general body function of women as well as their mood, thoughts, and behaviour are changed. During these periods, women physically become overweight and suffer discomfort whilst having an upset stomach and headaches. In addition, they have a lack of energy, feelings of guilt, hopelessness and being worthless, whilst perhaps crying without any specific reason. Moreover, the women think that they may not be good enough or they are not a deserving mother. Their behaviour changes are also clearly seen in their tendency for eating and sleeping less or more than usual, and for withdrawing from their husbands, family, and friends (Haring, Smith, Bodnar, \& Ryan, 2011). The similarity of such symptoms with pregnancy somatic symptoms causes possible neglect of depression in pregnancy and after childbirth. Therefore, non-somatic symptoms in women may be more helpful in diagnosing depression during these periods (Wichman \& Stern, 2015).

Numerous factors may increase the development of depression in the pregnancy and postpartum periods. Included are pre-pregnancy and pre-birth factors such as genetics, history of depression or any mental disorder, unwanted pregnancy, hormonal changes, lack of social and financial support, marital dissatisfaction, and relational conflicts with their own mother. Also included are birth factors like birth complications concerning foetus delivery and an ill baby, as well as postpartum factors such as the tiredness of the mother and a lack of sleep, possible feeding problems with the baby, and negative thoughts about the baby (Hutchens \& Kearney, 2020; Kettunen, Koistinen, \& Hintikka, 2016; Wichman \& Stern, 2015).

Resolving any of these factors, however, can prevent adverse effects on both mother and baby and the high-risk problems (Azami et al., 2018; Lewis, Galbally, \& Bailey, 2012; Weck, Paulose, \& Flaws, 2008). Without treatment the mother may face preeclampsia, problems in feeding and developing her relationship with her baby, and higher risk behaviours such as violence, alcohol or drug abuse, and suicide. Further, the baby may be born premature and with a lower weight than normal. In addition, depression during these periods can have an effect on the marital relationship (Kiani, Khadivzadeh, Sargolzaee, \& Behnam, 2010), social isolation (Lee \& Chung, 2007) and the development of the child (Goodman, Rouse, Long, Ji, \& Brand, 2011; Lewis et al., 2012). Thus, an accurate diagnosis of depression and proper treatment can cure depressed mothers and help them to recover and return to their normal life sooner.

Antidepressant medications are one of the treatments for depression. However, using medication during pregnancy and after needs clear instruction on how and when mothers are going to take such medication. Such treatment must be safe and effective and still ongoing 


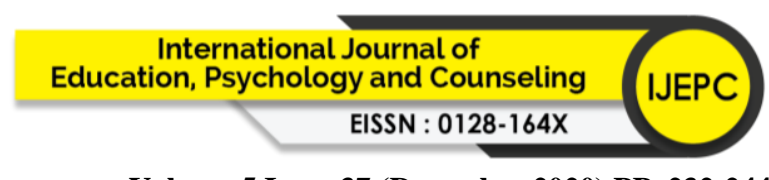

Volume 5 Issue 37 (December 2020) PP. 232-244

DOI 10.35631/IJEPC.5370019

because at the same time using medication may have side effects for both mother and foetus or baby. The effects can appear in the breast milk, or cause gestational diabetes, bleeding (Gotlib \& Hammen, 2008; Stewart, 2011), miscarriage, or preterm birth (Pearlstein, 2015).

Therefore, psychological therapies are preferred as alternatives to medication. Psychological interventions reduce the symptoms of depression and prevent the debilitating effects of depression during pregnancy on the pregnant woman and subsequently the child (Haring et al., 2011). Some specific therapeutic approaches such as interpersonal psychotherapy (IPT), supportive psychotherapy, conjoint therapy, and cognitive-behavioural therapies (CBT), are effective in treating depression (Gotlib \& Hammen, 2008; Wichman \& Stern, 2015). Acceptance and Commitment Therapy (ACT), as the new practical behavioural approach, has been involved in recent research as an effective treatment for depression during pregnancy and the postpartum period (Bonacquisti, Cohen, \& Schiller, 2017; Waters et al., 2020).

\section{Acceptance and Commitment Therapy (ACT)}

Acceptance and Commitment Therapy (ACT) is a postmodern, contextual change-based behavioural therapy that targets the suppression and avoidance of any unpleasant private event including thoughts, feelings, and bodily sensations (Hayes, Strosahl, \& Wilson, 1999). In contrast to the first two waves of behavioural therapies which were focused on decreasing and changing such experiences, ACT aims to increase psychological flexibilities in order to help clients make suitable choices in their certain actions and build their life based upon personal values (Hayes, Luoma, Bond, Masuda, \& Lillis, 2006). This change occurs over the six core stages of ACT, which are acceptance, cognitive diffusion, being present, self as context, values and behavioural commitment. This is when clients learn to stop avoiding and over thinking those experiences and instead, to be aware and mindfully accept them as part of the totality of the human experience. Once clients can experience their undesirable private events without any change, they learn to choose a way consistent with their values for facing the situation. In the last stage of behaviour change, clients learn to be always committed toward pursuing valued life directions and creating a meaningful life (Forman \& Herbert, 2009; Hayes et al., 2006; Hayes, Strosahl, \& Wilson, 2011; S. C. Hayes, Villatte, Levin, \& Hildebrandt, 2011). Thus, the results will be over the long run and see greater satisfaction in life in the face of different challenging experiences (Dindo, Van Liew, \& Arch, 2017). A number of different studies and meta-analyses, systematic, and narrative reviews have proven ACT as an effective therapeutic intervention for treating psychological disorders; and chronic pain (A-tjak et al., 2015; Eifert \& Forsyth, 2005; Feliu-Soler et al., 2018; Hayes, K. D. Strosahl, et al., 2011; Hughes, Clark, Colclough, Dale, \& McMillan, 2017; Jiménez, 2012; Powers, Vörding, \& Emmelkamp, 2009); quality of life (Stenhoff, Steadman, Nevitt, Benson, \& White, 2020); marital satisfaction (Peterson, Eifert, Feingold, \& Davidson, 2009); and behavioural change (Hayes, K. D. Strosahl, et al., 2011; Roche, Kroska, \& Denburg, 2019). ACT has identified as an empirically supported treatment for depression (Dindo et al., 2017; Strosahl \& Robinson, 2017). The efficacy of ACT for depression reduction has been investigated by many scholars among adolescents, adults (Chi, Bo, Liu, Zhang, \& Chi, 2018; Coto-Lesmes, Fernández-Rodríguez, \& González-Fernández, 2020; Fledderus, Bohlmeijer, Pieterse, \& Schreurs, 2012; Hayes, Boyd, \& Sewell, 2011; Kohtala, Lappalainen, Savonen, Timo, \& Tolvanen, 2015), and among pregnant and postpartum women, in particular (Waters et al., 2020). 


\section{Acceptance and Commitment Therapy for Depression during Pregnancy and Postpartum Periods}

As women attempt to avoid unpleasant experiences during pregnancy and postpartum periods, whether in thought, feelings, behaviour, or in bodily sensations, this can result in the development of distress and depression (Chawla \& Ostafin, 2007). Avoidance as a part of psychological inflexibility can be seen as efficient for women who feel the situation may be impossible to change. Such women cannot accept their physiological and psychological changes that occur during pregnancy and therefore, by overthinking they start to blame or accuse themselves and others. Further, they normally have low self-esteem and less emotional (Guardino \& Dunkel Schetter, 2014) and social supports (Khavari, Golmakani, Saki, \& Aghamohammadian Serbaf, 2018). The inability to elucidate their own values, using less of their abilities, and having marital problems (Azale, Fekadu, Medhin, \& Hanlon, 2018), problems in family relationships, and financial difficulties in raising the children (Guardino \& Dunkel Schetter, 2014), are among the factors that bring the feelings of worthlessness and hopelessness for some women during pregnancy and the postpartum period.

In the presence of depression during pregnancy and afterwards, ACT assists women to remain in contact with their unpleasant experiences rather than employing avoidance, and to approach those thoughts, feelings, behaviours, and bodily sensations. In fact, ACT aims to help the women to be conscious of their maternal changes and to observe any of their behaviour and reaction to negative cycles of the life and health of themselves and their baby.

Through such awareness, ACT also encourages women to mindfully accept their unpleasant experiences without change. Practicing mindfulness skills within an ACT approach enables women to pay attention to the present moment and help them to accept such experiences without any judgement. Mindfulness strategies disconnect a depressed person from overthinking, mind rumination and mind wandering (Farb et al., 2010) Instead, it fosters his/her present awareness and emotional acceptance (Strosahl \& Robinson, 2017). Moreover, mindfulness skills assist women to make a space between themselves and their thoughts and actions. In this way, the undesirable functions of such thoughts decrease, and those negative thoughts have less of a hold over the women. The women, therefore, accept and experience such thoughts as a part of the totality of the human experience, and consider them to be only harmless and uncomfortable passing events. Consequently, the women will neither judge them, nor themselves as a weak, guilty, or an undeserving mother.

Based on the behavioural change stages of ACT, once women become aware of and experience the unpleasant events without change and judgement, they would be truly enabled to control their internal experiences and have the power to choose the direction that they want their motherhood lives to take. However, they need to choose a way which is consistent with their values. ACT also helps the women to focus on and clarify their personal values, their own health values and that of the baby and the values gained from pregnancy. Such values can inspire the women to make suitable choices for certain actions.

In the last stage of behavioural change of ACT, the women learn to commit in acting in respect of those values, and therefore, to reach their goals and create a meaningful and qualified life for themselves and their babies. 


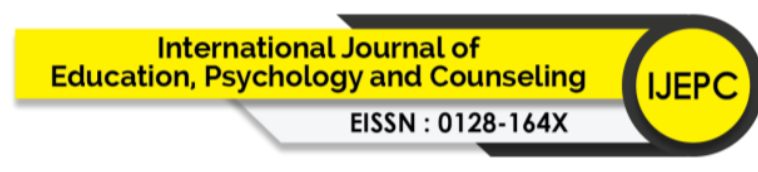

Volume 5 Issue 37 (December 2020) PP. 232-244

DOI 10.35631/IJEPC.5370019

Accordingly, such psychological flexibilities as a result of Acceptance and Commitment Therapy (ACT) significantly reduce the depression of women in both pregnancy and postpartum periods (Bonacquisti et al., 2017; Goodman et al., 2011; Waters et al., 2020). Cheraghian, Heidari, Ghedami, and Zarei (2015) stated that reducing experiential avoidance during the ACT interventions causes a change in depressive symptoms during pregnancy. The efficiency of ACT in reducing depression in pregnancy and postpartum, is also in its workability over the long run. In contrast to other strategies which are normally used to cope with depression during these times, ACT produces benefits that last long after treatment has stopped (Lappalainen et al., 2014). The feasibility of ACT within the daily routine practice setting of the women can be a significant reason for its long-term effects (Waters et al., 2020).

\section{ACT and Depression Reduction of Iranian Women during Pregnancy and Afterwards}

Recent research studies undertaken concerning ACT and reduction of depression amongst Iranian women during pregnancy and the postpartum period have shown that Acceptance and Commitment Therapy is an empirically supported and effective treatment for reducing depression.

Shojaeifar, Akbari Torkestani, and Jamiliyan (2019) investigated the efficacy of Acceptance and Commitment Therapy (ACT) on the postpartum depression of women who had unwanted pregnancies in Arak, Iran. In that study, a clinical trial with a pre/ post-test control group design and two months follow-up was carried out. The participants included 52 women who were in two to six months postpartum periods, ages between 18 to 45 years, with no background of depression, and having a diploma or higher educational levels. The participants also had unwanted pregnancy and medium depression (score 20 to 28). They were selected randomly and were assigned in experimental and control groups (each group $n=26$ ). The Beck Depression Inventory and an unwanted pregnancy questionnaire were used as instruments of that study for pre, post-test and delayed post-test. The intervention group attended 8 weekly ACT sessions (90 min, once a week). Chi-square and Mann-Whitney U tests were used for data analysis. The result showed there was significant differences between pre-test and post-test on depression between the experimental and control groups $(17.3 \pm 4.2$ and $26.5 \pm 3.1)$ and also the result of a two months delayed post-test were significantly different between the control and intervention group $(25.61 \pm 3.4$ vs. $12.4 \pm 3.8, P<.05)$. Based on the findings, the decrease in depression scores of the intervention group showed the efficacy of ACT for treating postpartum depression. The significant decrease of depression in the delayed post-test also indicated the feasibility of ACT over the long-term.

Abadi and Kalantari (2018) conducted a study to determine the effectiveness of Acceptance and Commitment Therapy on postpartum depression of the first pregnancy among women who live in Kashan, Iran. The research was semi-experimental with a pre/post-test and control group design. To achieve the purpose of that study, 30 women from 87 were chosen at random. Those 30 women, who all experienced their first pregnancy in Kashan in 2016, were randomly placed in two groups, experimental and control. The experimental group underwent 8 sessions (one month) of 90 minutes. The Edinburgh Postnatal Depression Scale was used as a pre and posttest in that study. The data was analysed using analysis of covariance (ANCOVA) with repeated measures. The results showed that there was a significant difference between the experimental group and the control group in terms of depression $(F=95.85, P<.0001)$. That study also aimed to determine the efficiency of ACT on self-esteem and body-image of the 


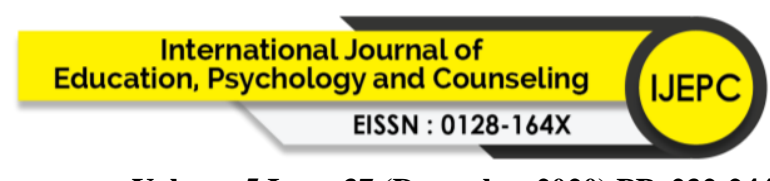

Volume 5 Issue 37 (December 2020) PP. 232-244

DOI 10.35631/IJEPC.5370019

women after the first birth for which the results were likewise different between the two groups. The findings of that study thus indicated that ACT treatment could be useful for mothers who were suffering from their maternal changes. This was because after the treatment they would not only stop avoiding their unpleasant events, but rather accept them and such acceptance could help in clarifying their values, accordingly, behaving and acting with respect to the values decreased their depression.

The study by Kazemeyni, Bakhtiari, and Nouri (2018) was conducted at the gynaecology specialised clinic of Isfahan among 32 women who recently delivered their babies. Similarly, the aim of their study was the determination of the level of depression of the women and their psychological flexibilities through ACT. The research was a clinical trial with pre-test, posttest and a two months follow-up. The instruments used for that research including the Beck Depression Inventory, the Edinburgh postpartum depression inventory and Acceptance and Action questionnaires. Inclusion criteria of that study were mothers between the ages of 20 to 40, with first time delivery, 4 weeks after delivery, and with a score of 17 or more in the Beck Depression Inventory (BDI-II $\geq 17$ ), and a score of 13 or more in the Edinburgh postpartum depression inventory (EPDS $\geq 13$ ). The participants were randomly divided into both experimental and control groups $(n=16)$. Based on ACT, the researchers conducted an 8session intervention (120 mins in a week). The participants responded to the questionnaire before and after the intervention and two months after the intervention. ANCOVA and repeated measures were used for data analysis. The results showed that acceptance and commitment significantly reduced depression and increased psychological flexibility $(p=.001)$ of the mothers in the experimental group. Based on the findings, the study stated that ACT intervention could be beneficial for treating postpartum depression and was recommended to psychologists and to women with postpartum depression (PPD).

Another study by Amini, Rezvani Zadeh, and Jelokhani Nakaraki (2018) also aimed at determining the efficiency of Acceptance and Commitment Therapy on depression as well as marital satisfaction in pregnant women of the Health Center of Tehran in 2015. That research was also semi-experimental with a pre/post-test and control group design. Some 30 women were selected for the sample of that study and they were randomly divided into two groups, experimental and control (each groups $n=15$ ). The instruments used in that study were the Beck Depression Inventory (21 questions) and the Enrich Marital Satisfaction Scale (47 questions). Treatment was conducted in eight sessions at the health clinic for the experimental group, but no intervention was applied to the control group. However, after treatment a posttest of two variables was performed for both groups. Both descriptive and inferential statistics through SPSS version 20 were used to analyse the data. Statistical analysis of covariance was also used to compare the mean depression and marital satisfaction of the pregnant women between the two groups based on the pre-test. The results of that study showed that the depression rate in the post-test scores of the treatment group were significantly lower than the pre-test, and at the same time, the marital satisfaction rate increased among women of the experimental group with no change in the control group. The result of covariance analysis also showed that the effectiveness of ACT on depression $(p<.001)$ and marital satisfaction $(p<$ .001) was significant. Such results have proven the workability of ACT in reducing depression during pregnancy. The findings also showed that there was a significant relationship between depression and marital satisfaction, in which by decreasing depression, then marital satisfaction increases. 


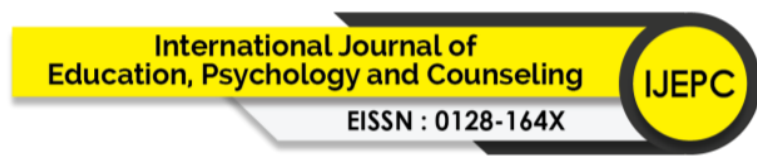

Volume 5 Issue 37 (December 2020) PP. 232-244

DOI 10.35631/IJEPC.5370019

Furthermore, Feyzi, Moradi, Khaje, and Khadem (2017) evaluated the effectiveness of Acceptance and Commitment Therapy on reducing anxiety and depression of pregnant women who were undergoing In Vitro Fertilisation (IVF). The research design of that study was semiexperimental with a pre/post-test and control group and a 4-week follow up. The sample was 35 women with primary or secondary infertility who became pregnant by IVF and were at 14 to 22 weeks of their pregnancy. This sample was randomly divided into experimental $(n=17)$ and control group $(n=18)$. The Structured Clinical Interview (SCID), Beck Depression Inventory (BDI-II), and Beck Anxiety Inventory (BAI) were the instruments of the study which were used for pre-test, post-test and delayed post-test. The experimental group underwent eight sessions of 90 minutes. However, the control group did not receive the treatment. The mixedANOVA test (SPANOVA) were used for data analysis. The results of the mixed analysis of variance test showed that there was a significant difference between anxiety and depression after ACT. Therefore, it was concluded that the intervention based on acceptance and commitment was effective in reducing anxiety and depression even among infertile women who became pregnant through IVF. Through the psychological flexibility gained by ACT, those women could mindfully accept the history of their infertility and had a better feeling about the process of In Vitro Fertilisation. Such acceptance could therefore help them to experience their pregnancy in consistence with their values. As a result, the anxiety and depression symptoms of the women reduced, and this reduction even remained one month later. The findings of that research were consistent with the results of the above studies in the workability of ACT over the long-term.

Lastly, the research of Cheraghian et al. (2015) also proved the efficacy of Acceptance and Commitment Therapy on reduction of depression during pregnancy. Similarly, that research was semi-experimental, with pre-test, post-test and a control group. The sample of 30 pregnant women from Valiasr Health Center in Delfan city, was randomly divided into two groups (each group $n=15$ ). The Beck Depression Inventory was used as an instrument of that study. The treatment was conducted once a week during eight sessions for the experimental group. However, the control group was not under any treatment. The Covariance method with a significance level of .01 was used in that research for testing the hypothesis. The result gained was significant differences in reducing depression through ACT between the experimental and control groups of which the rate of this effect was $60 \%$. $(F=59.50, p<.05)$.

The studies in this section provide a summary of the literature concerning the efficiency of Acceptance and Commitment Therapy (ACT) for reducing depression during pregnancy and the postpartum period among Iranian women. Consequently, the literature has proven the Acceptance and Commitment Therapy as an empirical-based psychological intervention which decreases the depression symptoms of Iranian women.

\section{Conclusion}

In conclusion, depression during pregnancy and after childbirth has a negative impact on both the mental and physical health of mother and baby. Such serious effect has fostered remarkable studies on depression in pregnancy and postpartum period. Reviewing of the related articles in several databases indicates that depression can be reduced through a proper treatment. Acceptance and Commitment Therapy (ACT) is an affective psychological intervention for treating depression during pregnancy and the postpartum period. The feasibility of ACT in reducing depression during pregnancy and afterwards is when women stop avoiding their 


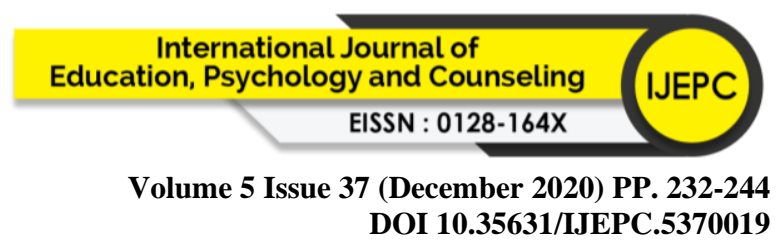

maternal changes, try to mindfully accept and experience such changes, and lastly, choose to behave consistent with their values. The commitment to always act with respect to their values, thus results in improving their health and to reduce depression.

This study has expanded the knowledge and deepened the understanding of the efficiency of ACT in reducing depression during pregnancy and the postpartum period, particularly among Iranian women. Future research efforts may present more impacts of ACT in terms of reducing depression during pregnancy and the postpartum period. Such research may also increase the literature relevant to depression and its reduction among Iranian pregnant women or new mothers.

\section{References}

A-tjak, J. G., Davis, M. L., Morina, N., Powers, M. B., Smits, J. A., \& Emmelkamp, P. M. (2015). A meta-analysis of the efficacy of acceptance and commitment therapy for clinically relevant mental and physical health problems. Psychotherapy and psychosomatics, 84(1), 30-36.

Abadi, B. R. A., \& Kalantari, M. (2018). Based on acceptance and commitment therapy on depression, self-esteem and body image concerns, after the first birth, women in Kashan city. Avicenna J Nurs Midwif Care, 26, 103-112.

Amini, M., Rezvani Zadeh, A., \& Jelokhani Nakaraki, R. (2018). Acceptance and Commitment Therapy on Depression and Marital Satisfaction in Pregnant Women. Middle Eastern Journal of Disability Studies, 8, 98-98.

Azale, T., Fekadu, A., Medhin, G., \& Hanlon, C. (2018). Coping strategies of women with postpartum depression symptoms in rural Ethiopia: a cross-sectional community study. Bmc Psychiatry, 18(1), 41.

Azami, M., Badfar, G., Shohani, M., Mansouri, A., Soleymani, A., Beigom Bigdeli Shamloo, M., . . . Parizad Nasirkandy, M. (2018). The prevalence of depression in pregnant Iranian women: A systematic review and meta-analysis. Iranian Journal of Psychiatry and Behavioral Sciences, 12(3), e9975.

Bahrami, N., \& Bahrami, S. (2013). Correlation between prenatal depression with delivery type and neonatal anthropometric indicators. Koomesh, 15(1), 39-45.

Barba-Müller, E., Craddock, S., Carmona, S., \& Hoekzema, E. (2019). Brain plasticity in pregnancy and the postpartum period: links to maternal caregiving and mental health. Archives of women's mental health, 22(2), 289-299.

Bonacquisti, A., Cohen, M. J., \& Schiller, C. E. (2017). Acceptance and commitment therapy for perinatal mood and anxiety disorders: development of an inpatient group intervention. Archives of women's mental health, 20(5), 645-654.

Bowen, A., Bowen, R., Butt, P., Rahman, K., \& Muhajarine, N. (2012). Patterns of depression and treatment in pregnant and postpartum women. The Canadian Journal of Psychiatry, 57(3), 161-167.

Carin, M., Lundgren, I., \& Bergbom, I. (2011). First time pregnant women's experiences in early pregnancy. International journal of qualitative studies on health and well-being, $6(2), 5600$.

Chawla, N., \& Ostafin, B. (2007). Experiential avoidance as a functional dimensional approach to psychopathology: An empirical review. Journal of clinical psychology, 63(9), 871890. 
Cheraghian, H., Heidari, N., Ghedami, S., \& Zarei, B. (2015). Efficacy of Acceptance and Commitment Therapy on Depressed Pregnant Women. Community Health journal, 9(2), 56-64.

Chi, X., Bo, A., Liu, T., Zhang, P., \& Chi, I. (2018). Effects of mindfulness-based stress reduction on depression in adolescents and young adults: a systematic review and metaanalysis. Frontiers in psychology, 9, 1034.

Coto-Lesmes, R., Fernández-Rodríguez, C., \& González-Fernández, S. (2020). Acceptance and Commitment Therapy in group format for anxiety and depression. A systematic review. Journal of Affective Disorders, 263, 107-120.

Dindo, L., Van Liew, J. R., \& Arch, J. J. (2017). Acceptance and commitment therapy: a transdiagnostic behavioral intervention for mental health and medical conditions. Neurotherapeutics, 14(3), 546-553.

Eifert, G. H., \& Forsyth, J. P. (2005). Acceptance and commitment therapy for anxiety disorders: A practitioner's treatment guide to using mindfulness, acceptance, and values-based behavior change: New Harbinger Publications.

Farb, N. A., Anderson, A. K., Mayberg, H., Bean, J., McKeon, D., \& Segal, Z. V. (2010). " Minding one's emotions: Mindfulness training alters the neural expression of sadness": Correction to Farb et al (2010).

Feliu-Soler, A., Montesinos, F., Gutiérrez-Martínez, O., Scott, W., McCracken, L. M., \& Luciano, J. V. (2018). Current status of acceptance and commitment therapy for chronic pain: a narrative review. Journal of pain research, 11, 2145.

Feyzi, Z., Moradi, A., Khaje, D. M., \& Khadem, N. (2017). The efficacy of Acceptance and Commitment Therapy (ACT) on Anxiety and Depression in infertile women who undergoing in Virto Fertilization (IVF).

Fledderus, M., Bohlmeijer, E. T., Pieterse, M. E., \& Schreurs, K. M. G. (2012). Acceptance and commitment therapy as guided self-help for psychological distress and positive mental health: a randomized controlled trial. Psychological medicine, 42(3), 485-495.

Forman, E. M., \& Herbert, J. D. (2009). New directions in cognitive behavior therapy: Acceptance-based therapies.

George, A., Luz, R. F., De Tychey, C., Thilly, N., \& Spitz, E. (2013). Anxiety symptoms and coping strategies in the perinatal period. BMC pregnancy and childbirth, 13(1), 233.

Goodman, S. H., Rouse, M. H., Long, Q., Ji, S., \& Brand, S. R. (2011). Deconstructing antenatal depression: what is it that matters for neonatal behavioral functioning? Infant Mental Health Journal, 32(3), 339-361.

Gotlib, I. H., \& Hammen, C. L. (2008). Handbook of depression: Guilford Press.

Guardino, C. M., \& Dunkel Schetter, C. (2014). Coping during pregnancy: a systematic review and recommendations. Health psychology review, 8(1), 70-94.

Hall, J. (2006). Spirituality at the beginning of life. Journal of clinical nursing, 15(7), 804-810.

Haring, M., Smith, J., Bodnar, D., \& Ryan, D. (2011). Coping with Depression during Pregnancy and Following the Birth: A Cognitive Behavior Therapy Based SelfManagement: BC Mental Health and Addiction Services, British Columbia. Retrieved from ....

Hayes, Boyd, C. P., \& Sewell, J. (2011). Acceptance and commitment therapy for the treatment of adolescent depression: A pilot study in a psychiatric outpatient setting. Mindfulness, 2(2), 86-94. 


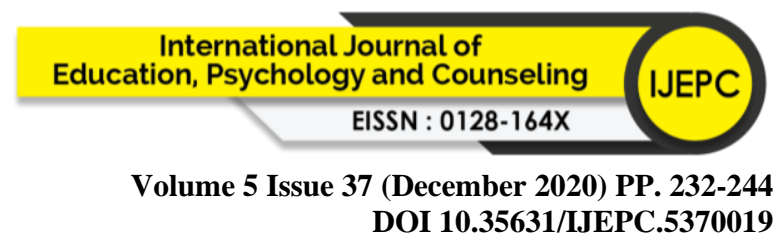

Hayes, Luoma, J. B., Bond, F. W., Masuda, A., \& Lillis, J. (2006). Acceptance and commitment therapy: Model, processes and outcomes. Behaviour research and therapy, 44(1), 1-25.

Hayes, Strosahl, K., \& Wilson, K. (1999). Acceptance and commitment therapy New York: Guilford Press.

Hayes, Strosahl, K. D., \& Wilson, K. G. (2011). Acceptance and commitment therapy: The process and practice of mindful change: Guilford Press.

Hayes, S. C., Villatte, M., Levin, M., \& Hildebrandt, M. (2011). Open, aware, and active: Contextual approaches as an emerging trend in the behavioral and cognitive therapies. Annual review of clinical psychology, 7.

Hughes, L. S., Clark, J., Colclough, J. A., Dale, E., \& McMillan, D. (2017). Acceptance and commitment therapy (ACT) for chronic pain. The Clinical journal of pain, 33(6), 552568.

Hutchens, B. F., \& Kearney, J. (2020). Risk factors for postpartum depression: an umbrella review. Journal of Midwifery \& Women's Health, 65(1), 96-108.

Jiménez, F. J. R. (2012). Acceptance and commitment therapy versus traditional cognitive behavioral therapy: A systematic review and meta-analysis of current empirical evidence. International journal of psychology and psychological therapy, 12(3), 333358.

Jorm, A., Allen, N., Morgan, A., \& Purcell, R. (2013). A guide to what works for depression: beyondblue.

Kazemeyni, M., Bakhtiari, M., \& Nouri, M. (2018). Effectiveness of acceptance and commitment group therapy on postpartum depression and psychological flexibility. Journal of Clinical Nursing and Midwifer, 4(3).

Kettunen, P., Koistinen, E., \& Hintikka, J. (2016). The connections of pregnancy-, delivery-, and infant-related risk factors and negative life events on postpartum depression and their role in first and recurrent depression. Depression research and treatment, 2016.

Khavari, F., Golmakani, N., Saki, A., \& Aghamohammadian Serbaf, H. (2018). The Relationship between Prenatal Coping Strategies and Irrational Beliefs in Pregnant Woman. Journal of Midwifery and Reproductive Health, 6(2), 1215-1222.

Kiani, F., Khadivzadeh, T., Sargolzaee, M. R., \& Behnam, H. (2010). Relationship between marital satisfaction during pregnancy and postpartum depression (PPD). The Iranian Journal of Obstetrics, Gynecology and Infertility, 13(5), 37-44.

Kingston, D., \& Tough, S. (2014). Prenatal and postnatal maternal mental health and schoolage child development: a systematic review. Maternal and Child Health Journal, 18(7), 1728-1741.

Kohtala, A., Lappalainen, R., Savonen, L., Timo, E., \& Tolvanen, A. (2015). A four-session acceptance and commitment therapy based intervention for depressive symptoms delivered by masters degree level psychology students: A preliminary study. Behavioural and Cognitive Psychotherapy, 43(3), 360.

Lam, R. W. (2018). Depression. : Third Edition. Oxford University Press.

Lappalainen, P., Granlund, A., Siltanen, S., Ahonen, S., Vitikainen, M., Tolvanen, A., \& Lappalainen, R. (2014). ACT Internet-based vs face-to-face? A randomized controlled trial of two ways to deliver Acceptance and Commitment Therapy for depressive symptoms: An 18-month follow-up. Behaviour research and therapy, 61, 43-54.

Lee, D. T., \& Chung, T. K. (2007). Postnatal depression: an update. Best Practice \& Research Clinical Obstetrics \& Gynaecology, 21(2), 183-191. 


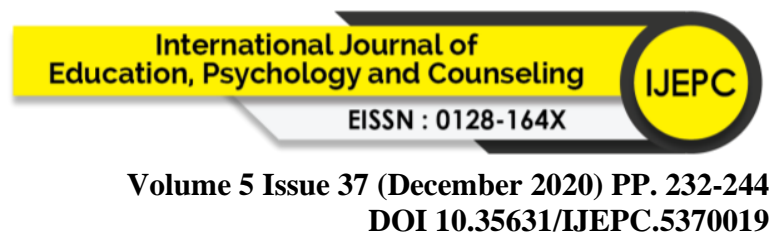

Lewis, A. J., Galbally, M., \& Bailey, C. M. (2012). Perinatal mental health, antidepressants and neonatal outcomes: findings from the Longitudinal Study of Australian Children. Neonatal, Paediatric \& Child Health Nursing, 15(3), 21.

Murray, C. J., Lopez, A. D., \& Organization, W. H. (1996). The global burden of disease: a comprehensive assessment of mortality and disability from diseases, injuries, and risk factors in 1990 and projected to 2020: summary: World Health Organization.

Pearlstein, T. (2015). Depression during pregnancy. Best Practice \& Research Clinical Obstetrics \& Gynaecology, 29(5), 754-764.

Peterson, B. D., Eifert, G. H., Feingold, T., \& Davidson, S. (2009). Using acceptance and commitment therapy to treat distressed couples: A case study with two couples. Cognitive and Behavioral Practice, 16(4), 430-442.

Powers, M. B., Vörding, M. B. Z. V. S., \& Emmelkamp, P. M. (2009). Acceptance and commitment therapy: A meta-analytic review. Psychotherapy and psychosomatics, 78(2), 73-80.

Roche, A. I., Kroska, E. B., \& Denburg, N. L. (2019). Acceptance-and mindfulness-based interventions for health behavior change: Systematic reviews and meta-analyses. Journal of Contextual Behavioral Science, 13, 74-93.

Setse, R., Grogan, R., Pham, L., Cooper, L. A., Strobino, D., Powe, N. R., \& Nicholson, W. (2009). Longitudinal study of depressive symptoms and health-related quality of life during pregnancy and after delivery: the Health Status in Pregnancy (HIP) study. Maternal and Child Health Journal, 13(5), 577-587.

Shi, Z., \& MacBeth, A. (2017). The effectiveness of mindfulness-based interventions on maternal perinatal mental health outcomes: a systematic review. Mindfulness, 8(4), 823-847.

Shojaeifar, S., Akbari Torkestani, N., \& Jamiliyan, H. (2019). Effect of Acceptance and Commitment Therapy on Postpartum Depression in Unwanted Pregnancies. Journal of Mazandaran University of Medical Sciences, 29(175), 47-56.

Slomian, J., Honvo, G., Emonts, P., Reginster, J.-Y., \& Bruyère, O. (2019). Consequences of maternal postpartum depression: A systematic review of maternal and infant outcomes. Women's Health, 15, 1745506519844044.

Stenhoff, A., Steadman, L., Nevitt, S., Benson, M. L., \& White, R. (2020). Acceptance and Commitment Therapy and Subjective Wellbeing: A Systematic Review and Metaanalyses of Randomised Controlled Trials in Adults. Journal of Contextual Behavioral Science.

Stewart, D. E. (2011). Depression during pregnancy. New England Journal of Medicine, 365(17), 1605-1611.

Strosahl, K. D., \& Robinson, P. J. (2017). The mindfulness and acceptance workbook for depression: Using acceptance and commitment therapy to move through depression and create a life worth living: New Harbinger Publications.

Veisani, Y., \& Sayehmiri, K. (2012). Prevalence of postpartum depression in Iran-A systematic review and meta-analysis. The Iranian Journal of Obstetrics, Gynecology and Infertility, 15(14), 21-29.

Waters, C. S., Annear, B., Flockhart, G., Jones, I., Simmonds, J. R., Smith, S., . . Williams, J. F. (2020). Acceptance and Commitment Therapy for perinatal mood and anxiety disorders: A feasibility and proof of concept study. British Journal of Clinical Psychology, e12261. 


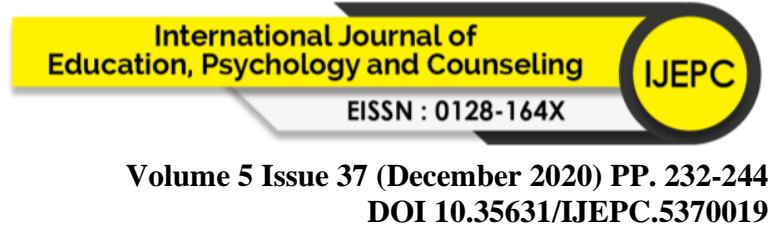

Weck, R. L., Paulose, T., \& Flaws, J. A. (2008). Impact of environmental factors and poverty on pregnancy outcomes. Clinical obstetrics and gynecology, 51(2), 349-359.

Wichman, C. L., \& Stern, T. A. (2015). Diagnosing and treating depression during pregnancy. The primary care companion for CNS disorders, 17(2).

World Health Organization. (2017). Depression and other common mental disorders: global health estimates

World Health Organization. (2020). Maternal Mental Health https://www.who.int/mental_health/maternal-child/maternal_mental_health/en/ 